\title{
Occupational exposure to endocrine disruptors and lymphoma risk in a multi-centric European study
}

L Costas ${ }^{\star}, 1,2,3$, C Infante-Rivard ${ }^{4}$, J-P Zock ${ }^{3,5,6,7}, \mathrm{M}$ Van Tongeren ${ }^{8}$, P Boffetta $^{9}$, A Cusson ${ }^{10}$, C Robles $^{1}$, D Casabonne ${ }^{1,3}, \mathrm{Y}$ Benavente ${ }^{1,3}, \mathrm{~N}$ Becker ${ }^{11}, \mathrm{P}$ Brennan $^{12}$, L Foretova ${ }^{13}$, M Maynadié $^{14}$, A Staines ${ }^{15}$, A Nieters ${ }^{16}, \mathrm{P} \mathrm{Cocco}^{17}$ and $\mathrm{S}$ de Sanjosé ${ }^{1,2,3}$

${ }^{1}$ Unit of Infections and Cancer, Cancer Epidemiology Research Programme, IDIBELL, Catalan Institute of Oncology, 08908 Barcelona, Spain; ${ }^{2}$ Department of Medicine, University of Barcelona, 08036 Barcelona, Spain; ${ }^{3}$ CIBER Epidemiologia y Salud Pública (CIBERESP), Madrid, Spain; ${ }^{4}$ Department of Epidemiology, Biostatistics and Occupational Health, Faculty of Medicine, McGill University, Montréal, QC, Canada H3A 1A2; ${ }^{5}$ Netherlands Institute for Health Services Research (NIVEL), 3500 Utrecht, The Netherlands; ${ }^{6}$ Centre for Research in Environmental Epidemiology (CREAL), 08003 Barcelona, Spain; ${ }^{7}$ Universitat Pompeu Fabra (UPF), 08003 Barcelona, Spain; ${ }^{8}$ Centre for Human Exposure Science (CHES), Institute of Occupational Medicine, EH14 4AP Edinburgh, UK; ${ }^{9}$ Tisch Cancer Institute and Institute for Translational Epidemiology, Icahn School of Medicine at Mount Sinai, New York, 10029 NY, USA; ${ }^{10}$ Centre de Recherche, CHU Sainte-Justine, Montréal, OC, Canada H3T 1C4; ${ }^{11}$ Division of Cancer Epidemiology, German Cancer Research Center, Im Neuenheimer Feld 280, 69120 Heidelberg, Germany; ${ }^{12}$ IARC, International Agency for Research on Cancer, 69372 Lyon, France; ${ }^{13}$ Cancer Epidemiology and Genetics, Masaryk Memorial Cancer Institute and MF MU, 65653 Brno, Czech Republic; ${ }^{14}$ Biological Hematology Unit, CRB Ferdinand Cabanne, Universitary Hospital of Dijon and EA4184, University of Burgundy, EA 4184 Dijon, France; ${ }^{15}$ Public Health University College, Dublin, Ireland; ${ }^{16}$ Centre of Chronic Immunodeficiency, Molecular Epidemiology, University Medical Center Freiburg, 79106 Freiburg, Germany and ${ }^{17}$ Department of Public Health, Clinical and Molecular Medicine, Occupational Health Section, University of Cagliari, 09124 Cagliari, Italy

Background: Incidence rates of lymphoma are usually higher in men than in women, and oestrogens may protect against lymphoma.

Methods: We evaluated occupational exposure to endocrine disrupting chemicals (EDCs) among 2457 controls and 2178 incident lymphoma cases and subtypes from the European Epilymph study.

Results: Over 30 years of exposure to EDCs compared to no exposure was associated with a $24 \%$ increased risk of mature B-cell neoplasms $(P$-trend $=0.02)$. Associations were observed among men, but not women.

Conclusions: Prolonged occupational exposure to endocrine disruptors seems to be moderately associated with some lymphoma subtypes.

Incidence rates of lymphoid neoplasms are usually higher in men than in women for most subtypes, especially T-cell lymphomas, multiple myeloma (MM) and chronic lymphocytic leukaemia (CLL; Smith et al, 2010). Immune suppression, which is the most well-established risk factor for lymphoma, and other possible risk factors, cannot explain this gender pattern. Human lymphocytes, as well as cells from some lymphoma subtypes, including Hodgkin lymphoma, MM, and CLL, can express oestrogen receptors (ERs)

*Correspondence: Dr L Costas; E-mail: Icostas@iconcologia.net

Received 25 September 2014; revised 2 January 2015; accepted 27 January 2015; published online 5 March 2015

(c) 2015 Cancer Research UK. All rights reserved 0007-0920/15 
$\alpha$ and $\beta$ (Yakimchuk et al, 2013). During their lifetime, women have higher hormone levels, such as oestrogens, which have been suggested to protect against lymphoma (Glaser et al, 2003; Costas et al, 2014), possibly contributing to this pattern.

Numerous synthetic chemicals used with different purposes, such as pesticides, cosmetics, plastic additives, and flame retardants, are capable of interfering with the endocrine system (Diamanti-Kandarakis et al, 2009). Some polychlorinated biphenyls (PCBs), pesticides, and solvents have been associated with an increased risk of lymphoma (Alexander et al, 2007). However, the role of other endocrine disrupting chemicals (EDCs) with potential oestrogenic, anti-oestrogenic, or anti-androgenic effect in lymphoma aetiology is unknown. Our aim was to explore the role of occupational exposure to agents with potential endocrine disrupting activity in lymphoma risk using the Epilymph study.

\section{MATERIALS AND METHODS}

Study design and population. The Epilymph study is a multicenter case-control study carried out in six European countries (Spain, France, Germany, Italy, Ireland, and Czech Republic) from 1998 to 2004. In Germany and Italy, selection of controls was accomplished using population registers, while in the other participating countries, controls were identified in the same hospital as cases. Participants with a history of organ transplantation, cancer (other than lymphoma) or known seropositive status for HIV were not included in the analyses. Overall, we included 2457 controls and 2178 incident lymphoma cases. Cases were coded with ICD-O-3, and were classified according to the most recent World Health Organization (WHO) Classification (Swerdlow, 2008; Turner et al, 2010). Instead of 'B-cell nonHodgkin lymphoma' as was customary, we refer to 'mature B-cell neoplasms' as in the WHO 2008 classification, this latter category includes MM and CLL in its definition. We mainly present results on mature B-cell neoplasm, as this is the largest lymphoma group. Secondary analyses stratified by subtype (including Hodgkin and T-cell neoplasms) can be found in the Supplementary Material. Additional details of the study design have been provided elsewhere (De Sanjosé et al, 2006).

Participants were interviewed face-to-face by trained interviewers using the same questionnaire in all countries. Participants listed all full-time jobs held for 1 year or longer. Industrial hygienists in each participating centre coded the occupations using the ISCO-68 coding system. Job codes were translated into the SOC 2000 coding system in order to apply a job-exposure matrix (JEM) for EDCs (Brouwers et al, 2009). Three experts assigned exposure probability scores for all chemical groups to each of the SOC job titles defined as 'unlikely', 'possible', and 'probable' based on their expertise and a previous bank of coded jobs (Van Tongeren et al, 2002). These scores refer to the probability that the occupational exposure level exceeded the background level (through diet, environment, or consumer products) in the general population (Brouwers et al, 2009). Supplementary Appendix 1 shows the occupational titles assigned to a possible or probable exposure to EDCs. Exposure assignment was blind to the case-control status and dichotomized into exposed (including exposures categorised as possible and probable) and unexposed. Forty-one participants did not report information on occupational exposures or the information was insufficient to classify exposure and they were excluded from these analyses. See Supplementary Appendix 2 for the most common occupations of controls and mature B-cell lymphoma according to their longest-held job. We evaluated exposure to several chemical groups with potential oestrogenic, anti-oestrogenic, or anti-androgenic effects including the following: polycyclic aromatic hydrocarbons, polychlorinated organic compounds (including PCBs), pesticides (organochlorines, carbamates, organophosphates, pyrethroids, and other pesticides), solvents (ethylene glycol ethers, styrene, toluene, xylene, trichloroethylene, and perchloroethylene), bisphenol-A, alkylphenolic compounds, brominated flame retardants, metals (arsenic, cadmium, copper, lead, and mercury), and a miscellaneous group (parabens, siloxans, and benzophenones).

Statistical analyses. Odds ratios (ORs) for lymphoma were computed as estimates of relative risk using unconditional logistic regression. All models were adjusted for age, sex, education, and country. Potential confounding effects of number of children, body mass index (BMI), ever smoking, regular intake of alcoholic beverages, and ever using hair dyes were examined, but none of them altered the estimates for mature B-cell neoplasms by more than $10 \%$. Because occupational exposure to solvents has been previously associated with lymphoma, we analysed associations among the unexposed to solvents, and we included ever exposure to organic solvents as a covariate in the regression models evaluating specific groups of chemicals. Duration, age at first exposure, and time since last exposure were calculated based on the years at start and stop reported for each job. Data were missing for $<5 \%$ of subjects for all variables, except for BMI, which reached $9 \%$ because its measure was introduced at a later stage in the study. We used generalised additive models to inspect the linearity of associations on duration of exposures. We used the MC-SIMEX method to correct estimates for measurement error of the exposure (Küchenhoff et al, 2006) fitting a quadratic regression to extrapolate the SIMEX OR estimate with no measurement error; a non-differential arbitrary sensitivity and specificity of $85 \%$ for binary exposures measured with the JEM were postulated as the misclassification probabilities.

\section{RESULTS}

Compared with controls, cases were less likely to report high BMI, and to have a lower parity (among women; Supplementary Table S1). Overall, we did not observe associations between lymphoma and ever workplace exposure to EDCs (Table 1 and Supplementary Table S2). Subjects occupationally exposed to any EDC at the time of interview (i.e., currently exposed) had a modestly elevated risk of mature B-cell lymphoma $(\mathrm{OR}=1.29,95 \%$ confidence interval $(\mathrm{CI})=1.04-1.60$, Table 1). Age at first exposure did not affect lymphoma risk. Duration of exposure to EDCs (i.e., years of work in jobs with exposure to EDCs) showed an upward trend in risk for mature B-cell lymphoma $(\mathrm{OR}=1.24,95 \% \mathrm{CI}=1.01-1.51$ for $>30$ years of exposure; $P$-trend $=0.02$, Table 1). Estimates for associations on duration of the exposure among the unexposed to solvents were of the same magnitude, although CIs were wide. Among the unexposed to pesticides, increased risks seemed to occur mainly after an exposure period of 10-30 years (Figure 1 and Supplementary Table S3). Among currently exposed workers, associations were observed for those exposed for 10 years or longer $(\mathrm{OR}=1.35,95 \% \mathrm{CI}=1.08-1.70)$, but not those exposed for less than 10 years $(\mathrm{OR}=0.97,95 \% \mathrm{CI}=0.62-1.53$; data not shown). Correcting for misclassification of exposure yielded an $\mathrm{OR}=1.32$ (95\% CI $=1.04-1.68)$ for $>10$ years of exposure (Supplementary Table S4).

Table 2 shows associations between mature B-cell neoplasms and a 10 years increase in exposure to individual chemicals. Significant associations were observed for each component in the pesticide group, as well as for ethylene glycol ethers, alkylphenolic ethoxylates, and copper. However, independent effects were difficult to assess due to the correlation between exposures (Supplementary Table S5 and Supplementary Figure S1). Increasing risks by duration of exposure were mostly observed among 
Table 1. Associations of occupational exposures to endocrine disruptors and risk of mature B-cell neoplasms

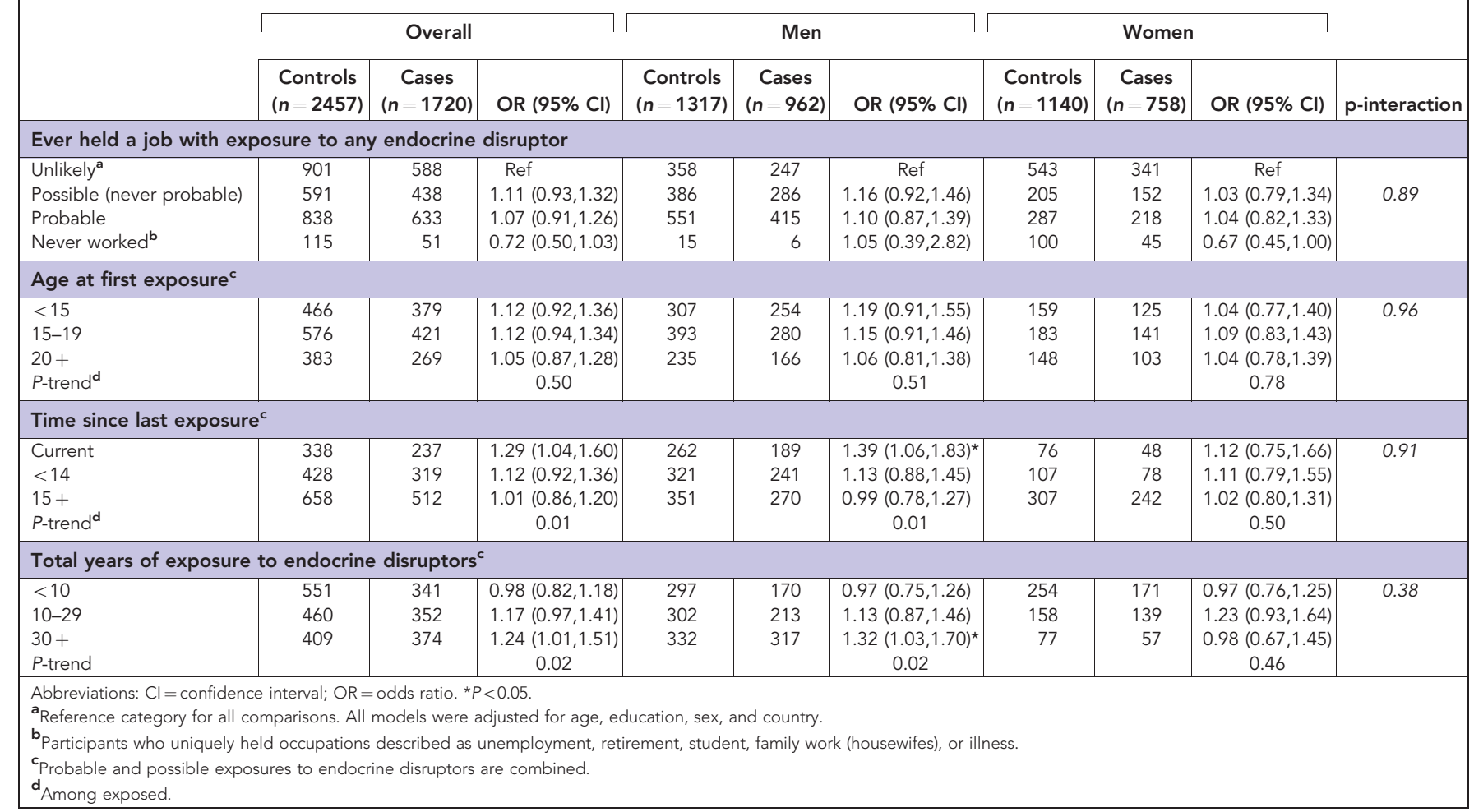
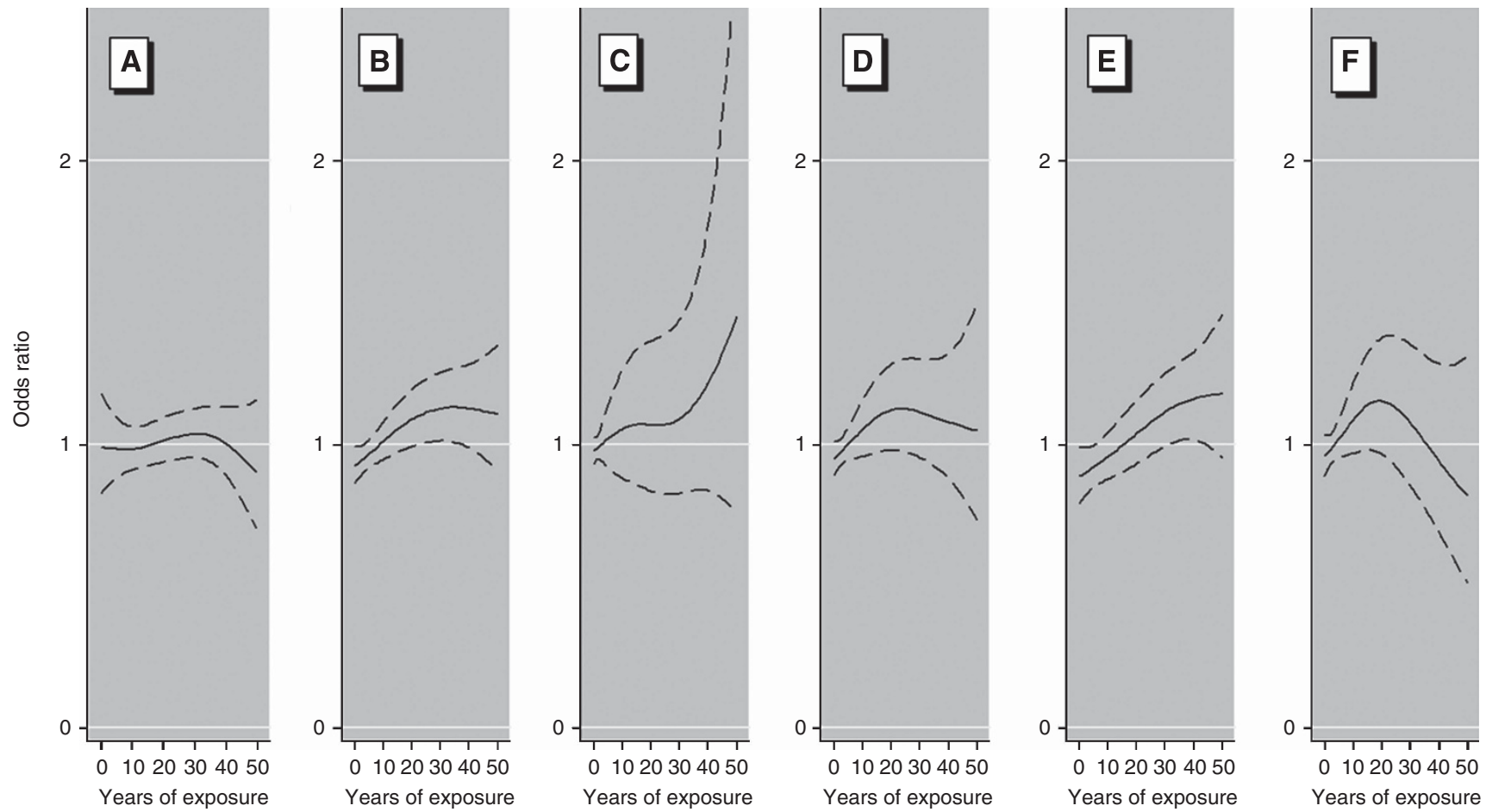

Figure 1. Smooth splines for the effect duration of occupational exposure to endocrine disruptors in generalised additive models with two cutpoints for mature B-cell lymphoma. Model adjusted for age, sex, country, and education level. Smooth estimates are represented in solid lines and $95 \%$ confidence intervals in dashed lines. Years of exposure $>50$ have been omitted from the graph (3.4\% of exposed participants). (A) Jobs without exposure to EDCs. (B) Jobs with exposure to any EDC. (C) Jobs with exposure to any EDC, excluding those participants exposed to solvents. (D) Jobs with exposure to any EDC, excluding those participants exposed to pesticides. (E) Jobs with exposure to any EDC, among males. (F) Jobs with exposure to any EDC, among females.

men, while associations were null among women; however, no significant interaction was detected between sex and exposure to EDCs (Tables 1 and 2). Analyses by lymphoma subtype showed associations with EDCs mainly among MM and CLL (Supplementary Tables S6 and S7). Mature T-cell neoplasms and Hodgkin lymphoma also showed associations with certain EDCs, 
Table 2. Duration of exposures to endocrine disruptors and risk of mature B-cell neoplasms. Estimates for 10 years increase of occupational exposure to endocrine disruptors

\begin{tabular}{|c|c|c|c|c|c|c|c|c|c|c|}
\hline & \multicolumn{3}{|c|}{ Overall } & \multicolumn{3}{|c|}{ Men } & \multicolumn{3}{|c|}{ Women } & \multirow[b]{2}{*}{ p-interaction } \\
\hline Total years of exposure to & Controls & Cases & $\begin{array}{c}\text { OR }^{a} \\
(95 \% \mathrm{Cl})\end{array}$ & Controls & Cases & $\begin{array}{c}\text { OR }^{a} \\
(95 \% \mathrm{Cl})\end{array}$ & Controls & Cases & $\begin{array}{c}\mathrm{OR}^{a} \\
(95 \% \mathrm{Cl})\end{array}$ & \\
\hline Unexposed $^{a}$ & 901 & 588 & Ref & 358 & 247 & Ref & 543 & 341 & Ref & \\
\hline \multicolumn{11}{|l|}{ Pesticides } \\
\hline Organochlorines & 442 & 347 & $1.10(1.00,1.20)^{\star}$ & 275 & 227 & $1.13(1.02,1.26)^{\star}$ & 167 & 120 & $1.00(0.85,1.17)$ & 0.13 \\
\hline Carbamates/pyrethroids & 507 & 391 & $1.11(1.02,1.21)^{\star}$ & 337 & 268 & $1.15(1.04,1.27)^{\star \star}$ & 170 & 123 & $0.99(0.84,1.16)$ & 0.11 \\
\hline Organophosphates & 467 & 366 & $1.10(1.01,1.20)^{\star}$ & 297 & 245 & $1.14(1.03,1.26)^{\star}$ & 170 & 121 & $1.00(0.85,1.17)$ & 0.11 \\
\hline \multicolumn{11}{|l|}{ Organic Solvents } \\
\hline Ethylene glycol ethers & 943 & 719 & $1.06(1.00,1.12)^{\star}$ & 595 & 454 & $1.08(1.01,1.16)^{\star}$ & 348 & 265 & $1.01(0.92,1.12)$ & 0.34 \\
\hline Styrene & 38 & 33 & $0.96(0.67,1.39)$ & 27 & 21 & $1.05(0.65,1.70)$ & 11 & 12 & $0.90(0.49,1.62)$ & 0.74 \\
\hline Toluene/xylene & 735 & 565 & $1.05(0.99,1.11)$ & 504 & 389 & $1.08(1.00,1.16)^{*}$ & 231 & 176 & $0.97(0.87,1.09)$ & 0.18 \\
\hline Trichloroethylene & 320 & 222 & $1.00(0.90,1.11)$ & 262 & 181 & $1.01(0.90,1.14)$ & 58 & 41 & $0.97(0.71,1.34)$ & 0.94 \\
\hline Perchloroethylene & 315 & 223 & $1.00(0.90,1.12)$ & 254 & 175 & $1.01(0.89,1.14)$ & 61 & 48 & $1.04(0.76,1.43)$ & 0.73 \\
\hline \multicolumn{11}{|l|}{ Alkylphenolic compounds } \\
\hline Alkylphenolic ethoxylates & 736 & 578 & $1.07(1.00,1.15)^{\star}$ & 393 & 298 & $1.11(1.02,1.22)^{\star}$ & 343 & 280 & $1.01(0.90,1.13)$ & 0.40 \\
\hline Alkylphenols & 466 & 379 & $1.06(0.98,1.16)$ & 285 & 238 & $1.12(1.01,1.24)^{\star}$ & 181 & 141 & $0.94(0.81,1.10)$ & 0.12 \\
\hline \multicolumn{11}{|l|}{ Metals } \\
\hline Cadmium & 108 & 77 & $0.90(0.69,1.19)$ & 62 & 64 & $0.89(0.66,1.20)$ & 16 & 13 & $0.89(0.35,2.25)$ & 0.67 \\
\hline Arsenic & 78 & 80 & $1.06(0.87,1.30)$ & 99 & 72 & $1.05(0.85,1.29)$ & 9 & 8 & $2.10(0.61,7.20)$ & 0.27 \\
\hline Copper & 824 & 617 & $1.07(1.00,1.14)^{\star}$ & 583 & 433 & $1.10(1.02,1.19)^{\star}$ & 241 & 184 & $0.97(0.84,1.11)$ & 0.14 \\
\hline Lead & 508 & 383 & $1.03(0.95,1.12)$ & 432 & 336 & $1.06(0.97,1.16)$ & 76 & 51 & $0.77(0.55,1.08)$ & 0.09 \\
\hline Mercury & 14 & 6 & $1.27(0.84,1.93)$ & 6 & 5 & $1.25(0.77,2.02)$ & 4 & 1 & $1.15(0.47,2.79)$ & 0.72 \\
\hline
\end{tabular}

such as alkylphenolic compounds (Supplementary Tables S2 and S7), while no significant associations were observed for FL or DLBCL.

\section{DISCUSSION}

In this large case-control study, we observed an increase in the risk for specific mature B-cell lymphoma subtypes with recent and prolonged occupational exposure to endocrine disruptors. Increased risks were observed among men, and associations were null among women, which could contribute to explaining the differences in lymphoma incidence between gender. Significant associations were observed for exposures to EDCs that lasted 30 years or more, while associations were null for exposures that lasted $<10$ years. Also, recent exposures were associated with an increased risk, while null risks were observed 15 years after the exposure. Associations with current exposures could reflect a better performance of the JEM for recent exposures. However, we would expect that the association with a recent + short exposure to EDCS would also be positive, whereas this association was null. This suggests that prolonged exposures may increase risk although this risk may decrease with increasing years after cessation of exposure. Reproductive hormones interact with lymphoid cells in several ways, and women produce a more vigorous cellular and humoral response than men (Bouman et al, 2005). Some lymphoma subtypes express ERs (Yakimchuk et al, 2013), and certain endocrine disruptors have been previously reported as lymphoma risk factors (Alexander et al, 2007). We observed associations with exposures to organic solvents, pesticides, certain metals, brominated flame retardants, and alkylphenolic compounds.

Among the EDCs included in the JEM that we applied, associations with lymphoma risk have been previously reported for PCBs, solvents, and pesticides, although with inconsistencies as some of the reports have been negative (Alexander et al, 2007). As only 11 subjects were classified as exposed to PCBs, our study was underpowered to explore the association with lymphoma risk. Our results partially overlap with a previous evaluation of occupational exposure to pesticides and solvents (including others than EDCs) and lymphoma risk, using the assessment of industrial hygienists (Cocco et al, 2010, 2013). They are significant and concordant with these former results, and other published papers (Alexander et al, 2007).

Other potential EDCs have rarely been assessed. The few human studies have been negative, inconsistent or too small to show an association with brominated flame retardants or with polycyclic aromatic hydrocarbons (Hardell et al, 1998; Cross et al, 2006; Yang et al, 2014). We observed significant associations with alkylphenolic compounds, which have been widely used in occupational settings as surfactant in cleaning agents, as well as in emulsion polymerisation, and textile and leather auxiliaries. Apart from oestrogenic and weak anti-androgenic activities (Kochukov et al, 2009; Luccio-Camelo and Prins, 2011), alkylphenols can interact with the immune system, increasing interleukin (IL)- 4 and TNF- $\alpha$, and suppressing IL-10, IFN- $\alpha$ and IFN- $\beta$ (Hung et al, 2013). Alkylphenolic compounds have been detected in blood or urine in approximately half of the adult population (Gyllenhammar et al, 2012), but their role in human health, including their carcinogenicity, is largely unknown. Our results also showed increased risks with increasing duration of exposure to metals, in particular for CLL. Some studies have suggested that working in metal-related jobs might increase risk of lymphoma (Band et al, 2004; Mester et al, 2006; 't Mannetje et al, 2008). However, some of these occupations have concomitant exposure to solvents, and previous studies have not determined whether associations were driven by solvents.

Our associations were consistent with the reported ER interaction scores of the different chemicals evaluated. ER interaction scores are constructed to reflect both potency and efficacy of EDCs in regard to their potential to interfere with the ER signalling pathway (Rotroff et al, 2014). ER interaction scores were higher for bisphenol-A (for which our study was underpowered), and alkylphenolic compounds (ER interaction 
score $=52$ and 51, respectively), and some of the pesticides, such as organochlorines (ER interaction score $=37$ ), while other chemicals had lower scores (Rotroff et al, 2014). However, our associations were moderate in magnitude, and other carcinogenic pathways may explain them. Apart from endocrine disruption, oxidative stress, DNA methylation, disruption of methyltransferases activity, and reduction of S-adenosyl-methionine, among others, have also been proposed for chemicals such as pesticides (Collotta et al, 2013). The main limitation of this study is the potential for misclassification of the exposure. However, in case of truly positive associations, this would result in the attenuation of estimates for binary and continuous exposures (Pearce et al, 2007), which would strengthen our conclusions, as supported by our sensitivity analyses with MC-SIMEX. Some of the reported associations may be due to chance because we have performed multiple comparisons. Also, independent effects were difficult to assess, as the exposures to different chemicals were correlated. Other routes of exposures, such as diet, might contribute to the EDCs intake, but we did not have dietary information. Strengths of our study include the large sample size that allowed us to analyse exposures using an updated classification of lymphoma subtypes. Also, we have evaluated a large number of chemicals not previously assessed as lymphoma risk factors, exploring new hypotheses on possible aetiological mechanism of lymphoma development.

In conclusion, this is, to our knowledge, the first comprehensive study assessing the occupational exposure to EDCs and lymphoma risk. We assessed exposure to chemicals with potential endocrine disrupting properties, using a large sample size and accurate information on histological subtypes. We observed associations with some lymphoma subtypes for recent and prolonged exposures to several EDCs. Studies using a more detailed exposure assessment are warranted.

\section{ACKNOWLEDGEMENTS}

We thank all those who took part in this study providing questionnaire data. We acknowledge funds provided by the University of Barcelona for the Research Abroad Grant 2012 and a Rio Hortega (CM13/00232) from the Spanish Ministry of Economy and Competitiveness (Carlos III Institute of Health) granted to LC. This work was partially supported by the public grants from Health Ministry of Spain (PI11/01810 and PI14/ 01219), Catalan Government (2009SGR1465 and 2014SGR756), European Commission 5th Framework Programme (QLK4-CT2000-00422); 6th Framework Programme ( FOOD-CT-2006023103); Carlos III Institute of Health (FIS PI081555, RCESP C03/09, RTICESP C03/10, RTICRD06/0020/0095 and CIBERESP); Marató TV3 Foundation (051210); International Agency for Research on Cancer (IARC-5111); MH CZ - DRO (MMCI, 00209805), RECAMO CZ.1.05/2.1.00/03.0101; Fondation de France (1999 008471; EpiLymph-France); Italian Association for Cancer Research (AIRC, Investigator Grant 11855); Italian Ministry of Education, University and Research, PRIN programme (2007WEJLZB, 20092ZELR2); and the German Federal Office for Radiation Protection (StSch4261 and StSch4420; EpilymphGermany).

\section{CONFLICT OF INTEREST}

PB provided expert testimony and consulted with government and private organizations on lymphoma risk and exposure to potential endocrine disruptors, including solvents and PCB. The remaining authors declared no conflict of interest.

\section{REFERENCES}

Alexander DD, Mink PJ, Adami H-O, Chang ET, Cole P, Mandel JS, Trichopoulos D (2007) The non-Hodgkin lymphomas: a review of the epidemiologic literature. Int J Cancer 120(Suppl 12): 1-39.

Band PR, Le ND, Fang R, Gallagher R (2004) Identification of occupational cancer risks in British Columbia: a population-based case-control study of 769 cases of non-Hodgkin's lymphoma analyzed by histopathology subtypes. J Occup Environ Med 46: 479-489.

Bouman A, Heineman MJ, Faas MM (2005) Sex hormones and the immune response in humans. Hum Reprod Update 11: 411-423.

Brouwers MM, van Tongeren M, Hirst AA, Bretveld RW, Roeleveld N (2009) Occupational exposure to potential endocrine disruptors: further development of a job exposure matrix. Occup Environ Med 66: 607-614.

Cocco P, Satta G, Dubois S, Pili C, Pilleri M, Zucca M, t’ Mannetje AM, Becker N, Benavente Y, de Sanjosé S, Foretova L, Staines A, Maynadié M, Nieters A, Brennan P, Miligi L, Ennas MG, Boffetta P (2013) Lymphoma risk and occupational exposure to pesticides: results of the Epilymph study. Occup Environ Med 70: 91-98.

Cocco P, t' Mannetje A, Fadda D, Melis M, Becker N, de Sanjosé S, Foretova L, Mareckova J, Staines A, Kleefeld S, Maynadié M, Nieters A, Brennan P, Boffetta P (2010) Occupational exposure to solvents and risk of lymphoma subtypes: results from the Epilymph case-control study. Occup Environ Med 67: 341-347.

Collotta M, Bertazzi PA, Bollati V (2013) Epigenetics and pesticides. Toxicology 307: 35-41.

Costas L, de Sanjosé S, Infante-Rivard C (2014) Reproductive factors and nonHodgkin lymphoma: a systematic review. Crit Rev Oncol Hematol 92(3): 181-193.

Cross AJ, Ward MH, Schenk M, Kulldorff M, Cozen W, Davis S, Colt JS, Hartge P, Cerhan JR, Sinha R (2006) Meat and meat-mutagen intake and risk of non-Hodgkin lymphoma: results from a NCI-SEER case-control study. Carcinogenesis 27: 293-297.

De Sanjosé S, Benavente Y, Nieters A, Foretova L, Maynadié M, Cocco PL, Staines A, Vornanen M, Boffetta P, Becker N, Alvaro T, Brennan P (2006) Association between personal use of hair dyes and lymphoid neoplasms in Europe. Am J Epidemiol 164: 47-55.

Diamanti-Kandarakis E, Bourguignon J-P, Giudice LC, Hauser R, Prins GS, Soto AM, Zoeller RT, Gore AC (2009) Endocrine-disrupting chemicals: an Endocrine Society scientific statement. Endocr Rev 30: 293-342.

Glaser SL, Clarke CA, Nugent RA, Stearns CB, Dorfman RF (2003) Reproductive factors in Hodgkin's disease in women. Am J Epidemiol 158: 553-563.

Gyllenhammar I, Glynn A, Darnerud PO, Lignell S, van Delft R, Aune M (2012) 4-Nonylphenol and bisphenol A in Swedish food and exposure in Swedish nursing women. Environ Int 43: 21-28.

Hardell L, Lindström G, van Bavel B, Wingfors H, Sundelin E, Liljegren G (1998) Concentrations of the flame retardant 2,2',4,4'-tetrabrominated diphenyl ether in human adipose tissue in Swedish persons and the risk for non-Hodgkin's lymphoma. Oncol Res 10: 429-432.

Hung C-H, Yang S-N, Wang Y-F, Liao W-T, Kuo P-L, Tsai E-M, Lee C-L, Chao Y-S, Yu H-S, Huang S-K, Suen J-L (2013) Environmental alkylphenols modulate cytokine expression in plasmacytoid dendritic cells. PLoS One 8: e73534.

Kochukov MY, Jeng Y-J, Watson CS (2009) Alkylphenol xenoestrogens with varying carbon chain lengths differentially and potently activate signaling and functional responses in GH3/B6/F10 somatomammotropes. Environ Health Perspect 117: 723-730.

Küchenhoff H, Mwalili SM, Lesaffre E (2006) A general method for dealing with misclassification in regression: the misclassification SIMEX. Biometrics 62: 85-96.

Luccio-Camelo DC, Prins GS (2011) Disruption of androgen receptor signaling in males by environmental chemicals. J Steroid Biochem Mol Biol 127: 74-82.

Mester B, Nieters A, Deeg E, Elsner G, Becker N, Seidler A (2006) Occupation and malignant lymphoma: a population based case control study in Germany. Occup Environ Med 63: 17-26.

Pearce N, Checkoway H, Kriebel D (2007) Bias in occupational epidemiology studies. Occup Environ Med 64: 562-568.

Rotroff DM, Martin MT, Dix DJ, Filer DL, Houck KA, Knudsen TB, Sipes NS, Reif DM, Xia M, Huang R, Judson RS (2014) Predictive endocrine testing in the 21st century using in vitro assays of estrogen receptor signaling responses. Environ Sci Technol 48: 8706-8716. 
Smith A, Roman E, Howell D, Jones R, Patmore R, Jack A. Network HMR (2010) The Haematological Malignancy Research Network (HMRN): a new information strategy for population based epidemiology and health service research. Br J Haematol 148: 739-753.

Swerdlow SH. International Agency for Research on CancerWorld Health Organization (2008) WHO classification of tumours of haematopoietic and lymphoid tissues. International Agency for Research on Cancer: Lyon, France.

't Mannetje A, Dryson E, Walls C, McLean D, McKenzie F, Maule M, Cheng S, Cunningham C, Kromhout H, Boffetta P, Blair A, Pearce N (2008) High risk occupations for non-Hodgkin's lymphoma in New Zealand: case-control study. Occup Environ Med 65: 354-363.

Turner JJ, Morton LM, Linet MS, Clarke CA, Kadin ME, Vajdic CM, Monnereau A, Maynadié M, BC-H Chiu, Marcos-Gragera R, Costantini AS, Cerhan JR, Weisenburger DD (2010) InterLymph hierarchical classification of lymphoid neoplasms for epidemiologic research based on the WHO classification (2008): update and future directions. Blood 116: e90-e98.
Van Tongeren M, Nieuwenhuijsen MJ, Gardiner K, Armstrong B, Vrijheid M, Dolk H, Botting B (2002) A job-exposure matrix for potential endocrinedisrupting chemicals developed for a study into the association between maternal occupational exposure and hypospadias. Ann Occup Hyg 46: 465-477.

Yakimchuk K, Jondal M, Okret S (2013) Estrogen receptor $\alpha$ and $\beta$ in the normal immune system and in lymphoid malignancies. Mol Cell Endocrinol 375: 121-129.

Yang F, Xiong J, Jia X-E, Gu Z-H, Shi J-Y, Zhao Y, Li J-M, Chen S-J, Zhao W-L (2014) GSTT1 deletion is related to polycyclic aromatic hydrocarbons-induced DNA damage and lymphoma progression. PLoS One 9: e89302.

This work is published under the standard license to publish agreement. After 12 months the work will become freely available and the license terms will switch to a Creative Commons AttributionNonCommercial-Share Alike 4.0 Unported License.

Supplementary Information accompanies this paper on British Journal of Cancer website (http://www.nature.com/bjc) 